\title{
Stability of steel reinforced soil walls after footing failure
}

1 Richard J. Bathurst PhD

Professor and Research Director, GeoEngineering Centre at Queen'sRMC, Department of Civil Engineering, Royal Military College of Canada, Kingston, Ontario, Canada

2 Yoshihisa Miyata DEng

Professor, Department of Civil and Environmental Engineering, National Defense Academy, Yokosuka, Japan

3 Yoshinori Otani BEng, PEng Team Manager, Reinforced Earth Division, Hirose Corporation, Tokyo, Japan
4 Hitoshi Ohta BEng

Director and General Manager, Technical Division, JFE Shoji Terre One Corporation, Tokyo, Japan

5 Hiroaki Miyatake BEng

Team Leader, Construction Technology Research Team, Public Works Research Institute, Tsukuba, Japan
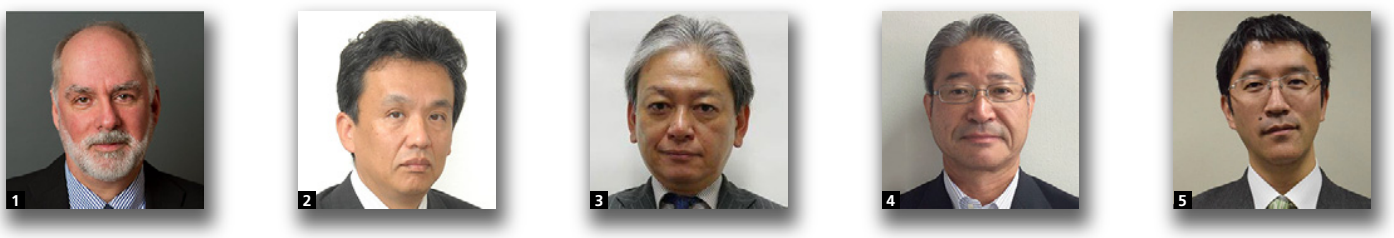

Two nominal identical $4 \mathrm{~m}$ high steel strip reinforced soil walls varying only with respect to reinforcement layer length arrangement were constructed and instrumented in an indoor laboratory environment. A novel feature of the tests was a foundation arrangement that allowed for simulated loss of toe support. Both walls performed well at the end of construction (EOC). Predicted unfactored maximum reinforcement tensile loads at the EOC using four different load models were judged to be conservative (safe for design) based on comparison with measured loads for both walls. Reinforcement loads were observed to increase with decreasing toe support, particularly at the base of the walls. A fully developed composite soil failure mechanism propagating from the heel of the foundation bulkhead and behind the reinforcement layers was observed during excavation of the stepped base wall model. There were no visual indications of soil failure within or behind the wall with longer uniform reinforcement lengths. However, predicted EOC loads for this wall were exceeded for most layers after loss of toe support. Implications for the design, analysis and performance of steel strip reinforced soil walls with similar reinforcement arrangements constructed over initially competent soil foundations and then subject to loss of toe support are identified.

\section{Notation}

$C_{\mathrm{c}} \quad$ coefficient of curvature

$C_{\mathrm{u}} \quad$ coefficient of uniformity

$D_{10} \quad$ particle size for which $10 \%$ of particle sizes are smaller

$D_{50} \quad$ particle size for which $50 \%$ of particles are smaller

$D_{85} \quad$ particle size for which $85 \%$ of particles are smaller

$D_{\max } \quad$ maximum particle size

$F_{\mathrm{H}} \quad$ horizontal force acting against the bulkhead

$H \quad$ wall height

$L \quad$ length of reinforcement

$q \quad$ foundation pressure

$S_{\mathrm{v}} \quad$ vertical spacing

$T_{\max } \quad$ maximum load

$z \quad$ depth below crest of wall

$\gamma \quad$ bulk unit weight of soil

$\phi \quad$ peak friction angle

\section{Introduction}

Reinforced soil walls that use steel strips as the internal reinforcing elements are now a proven and accepted technology to perform the earth retaining wall function. Design methods for conventional structures of this type are now well established and can be found in design guidance documents issued in different countries such as the USA (AASHTO, 2014), Canada (CGS, 2006), Japan (PWRC, 2014), the UK (BSI, 2010) and Hong Kong (GEO, 2002). A common feature of these codes is that the foundation at the toe of the wall is assumed to remain unchanged for the life of the structure. However, it is possible that loss of support in the vicinity of the toe can occur due to unforeseen excavations, scour, downslope movement of soil in front of the wall or bearing capacity failure of the footing at the base of the wall facing. Scour appears to be the most common cause of toe failure 
(Alzamora and Anderson, 2009; Berg et al., 2009). Loss of support can lead to additional loads on the internal reinforcing layers that were not anticipated at the time of design. These additional loads can lead to a serviceability failure (e.g. unacceptable wall movement) or even collapse of the structure.

The study described in this paper is focused on the behaviour of two full-scale steel strip walls that were constructed with two different reinforcement arrangements and seated on the same foundation. Following construction, an instrumented bulkhead located below the toe of the wall was moved laterally in stages to simulate loss of toe support. Bulkhead loads, wall deformations, backfill settlement, reinforcement loads and earth pressures were recorded during construction and during lateral displacement of the foundation bulkhead. Measured reinforcement loads at the end of construction (EOC) and during toe release were compared with values predicted using current design methods. Implications for internal stability design and performance of steel strip reinforced soil walls for the case of loss of toe support are discussed. Similar studies using the same full-scale test arrangement but with different facing types in combination with (polymeric) geogrid and steel multi-anchor soil reinforcement materials have been reported by Miyata et al. (2015) and Bathurst et al. (2015).

The data used in the current investigation are from an unpublished internal report (PWRC, 1995) and data found in the archives of the Public Works Research Institute (PWRI) in Japan. Short summaries of some test results have appeared in Japanese language conference papers (Kumada et al., 1994; Onodera et al., 1994). The walls were constructed at the PWRI test site in Japan as part of a series of test walls constructed with different geogrid and steel soil reinforcement products. Details of the other steel walls in the series can be found in earlier papers by the authors (Miyata and Bathurst, 2009, 2012a). The wall designations in the current study match those reported by Miyata and Bathurst (2009). However, the test results in this earlier work were restricted to wall behaviour prior to toe release (EOC) only. These earlier data were included with measurements from other instrumented steel strip walls to compile a database of steel strip reinforced soil wall performance for structures seated on competent foundations.

\section{Experimental programme}

\subsection{General}

The test configurations for the two walls in this investigation are shown in Figure 1. Each wall was $4 \mathrm{~m}$ in height $(H)$ and $5 \mathrm{~m}$ wide. The figure shows the $2 \mathrm{~m}$ deep foundation bulkhead that was located below the toe of the structures. A schematic illustration of the instrumented bulkhead is shown in Figure 2. The footing at the base of the wall face was a steel beam supported by slider joints constructed

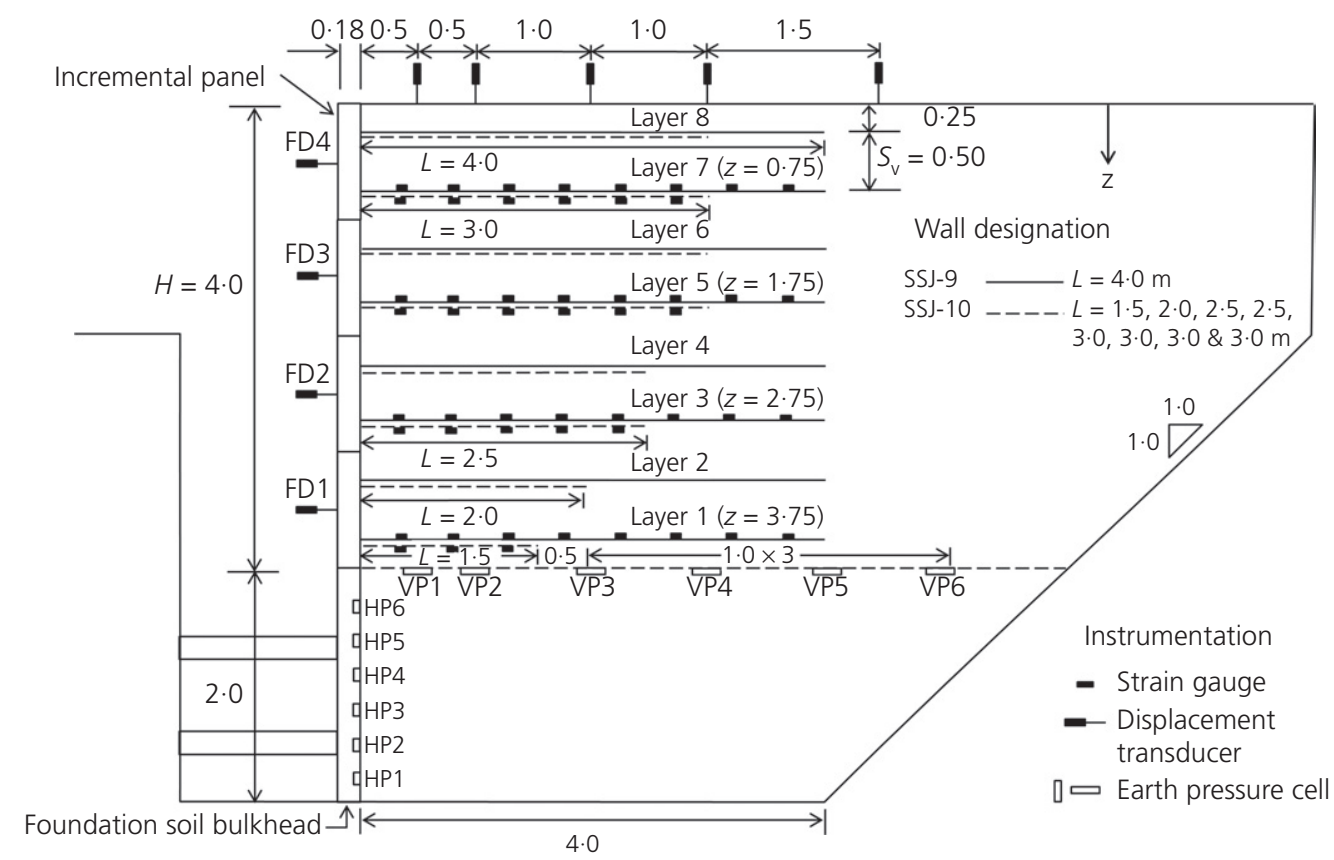

Figure 1. General test arrangement for steel strip wall SSJ-9

( $L=4 \mathrm{~m}$ ) and SSJ-10 ( $L$ variable). The foundation bulkhead was moved to the left during release of foundation support

(dimensions in $\mathrm{m}$ ) 


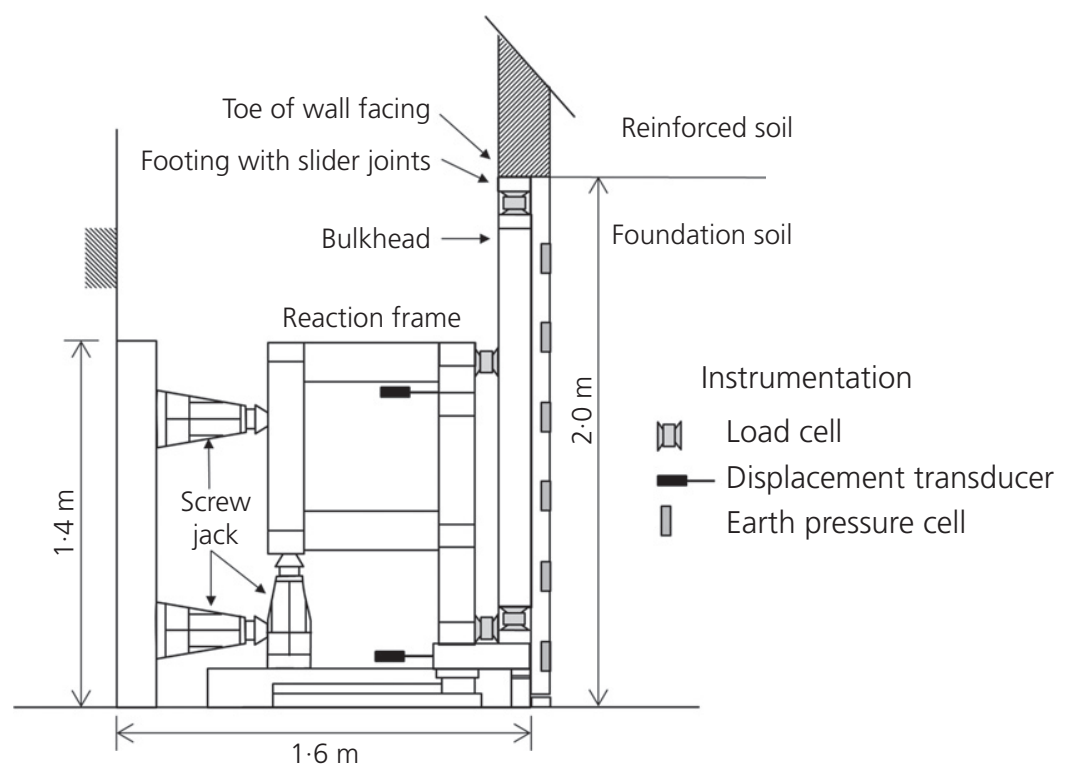

Figure 2. Detail of foundation soil bulkhead support and wall footing

from linear plate bearings and seated on a pair of load cells. This arrangement decoupled horizontal loads acting against the facing panels from the horizontal loads developed against the foundation bulkhead. The walls were constructed without external support with the exception of temporary bracing during placement and backfilling of the first panel.

The soil type and compaction were the same for the two walls in the current study. Kasumigaseki River sand with a fines content of $8 \%$ was used for the backfill and foundation soil. The particle size distribution showed $D_{\max }=2 \mathrm{~mm}$, $D_{85}=1.2 \mathrm{~mm}, D_{50}=0.33 \mathrm{~mm}, D_{10}=0.078 \mathrm{~mm}$, coefficient of uniformity, $C_{\mathrm{u}}=4.5$ and coefficient of curvature $C_{\mathrm{c}}=1 \cdot 6$. The sand is SP type according to USCS designations. Compaction was carried out in $0.25 \mathrm{~m}$ lifts using a $65 \mathrm{~kg}$ walk-behind vibrating plate compactor. Moisture contents were in the range $3-4 \%$. The soil was compacted to satisfy a minimum of $90 \%$ of Proctor dry density, which corresponds to a bulk unit weight of $16.0 \mathrm{kN} / \mathrm{m}^{3}$. The sand cone method was used to measure as-compacted sand densities. Conventional consolidated-drained triaxial compression tests were carried out to estimate strength parameters for the backfill. From these tests, a cohesion value of $2 \mathrm{kPa}$ and a peak friction angle $(\phi)$ of $38^{\circ}$ were deduced (see Figure $\mathrm{S} 1$ in the supplementary data to this paper).

Each wall took 5 days to construct. Thereafter, the bulkhead shown in Figure 2 was released in a controlled manner to allow horizontal movement of the $2 \cdot 0 \mathrm{~m}$ thick depth of foundation soil.

\subsection{Test walls}

The steel reinforcement strips in both walls were placed at centre-to-centre vertical and horizontal spacings of $0.50 \mathrm{~m}$. The concrete facing panels were of size $1 \mathrm{~m} \times 1 \mathrm{~m}$ and $180 \mathrm{~mm}$ thickness. Wall SSJ-9 was constructed with a uniform length of reinforcement $(L=4 \mathrm{~m})$ with a length to height ratio $L / H=1$. Wall SSJ-10 was constructed with a stepped base reinforcement configuration with variable length of reinforcement strips from $1 \cdot 5-3.0 \mathrm{~m}$, as shown in Figure 1. The steel strips were ribbed type and were $60 \mathrm{~mm}$ wide and $5 \mathrm{~mm}$ thick. The ribs were $3 \mathrm{~mm}$ high and located on top and bottom of the strips. The ribs were arranged in pairs $47 \mathrm{~mm}$ apart and pairs of ribs were centred at $110 \mathrm{~mm}$.

The use of constant reinforcement lengths as in wall SSJ-9 is typical recommended practice although reinforcement length to wall height ratios of $L / H=0.6$ or 0.7 are more common, at least for the purpose of initial sizing. The conservative length (i.e. $L / H=1$ ) was purposely chosen to avoid a potential composite failure through the reinforced soil zone and the foundation soil that could complicate the interpretation of test results.

Steel strip reinforced soil walls have been constructed in the field with reduced (stepped base) reinforcement lengths (Bathurst et al., 2009, 2011). The commentary in the guidance document used in the USA (AASHTO, 2014) points out that there is no theoretical basis for uniform reinforcement lengths, but notes that uniform reinforcement lengths are a common feature of many successful wall designs in the past. BS 8006 (BSI, 2010) recommends their use only when good foundation 
conditions exist. Geoguide 6 (GEO, 2002) describes the use of stepped base reinforcement layers only for the case of excavations into competent rock. The Public Works Research Center (PWRC, 2014) gives recommendations for stepped base reinforcement lengths that require that the minimum length be the greater of $4 \mathrm{~m}$ or $0.4 H$. This condition is not satisfied for wall SSJ-10. The non-conservative stepped base reinforcement length configuration for wall SSJ-10 was purposely chosen to investigate the combined effect of loss of toe support and short reinforcement length at the base of the reinforced soil zone on wall performance. If the empirical recommendations for minimum reinforcement length recommended by PWRC (2014) are ignored, the anchorage lengths for all layers are adequate for the EOC condition based on the geometry of the internal bilinear wedge used for design and discussed later.

\section{Results}

Figure 3 shows the horizontal bulkhead loads, the sum of reinforcement tensile loads (from instrumented layers) and vertical bulkhead loads recorded during horizontal displacement of the bulkhead. The horizontal bulkhead loads were recorded

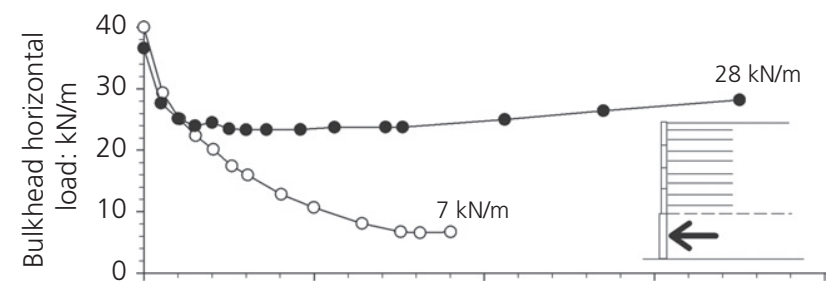

(a)

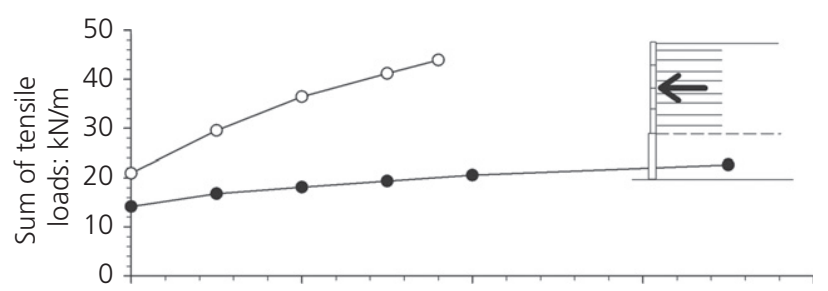

(b)

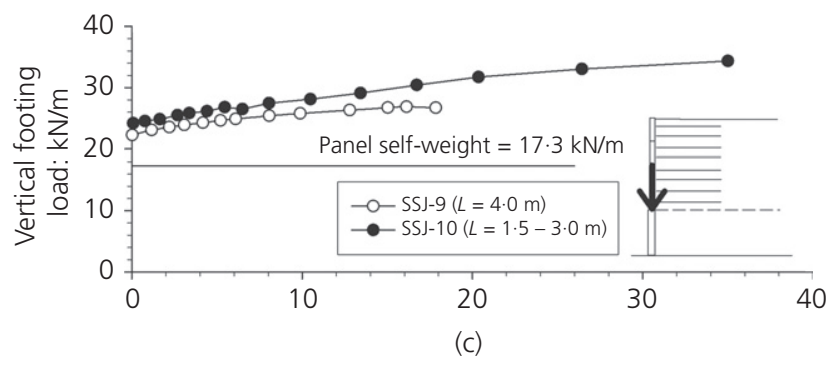

Horizontal displacement of bulkhead: $\mathrm{mm}$

Figure 3. Measured loads at EOC and during horizontal bulkhead displacement: (a) horizontal foundation bulkhead load; (b) sum of reinforcement loads from instrumented reinforcement layers;

(c) vertical footing load at top of bulkhead using load cells at the back of the bulkhead. The trends in values were consistent with loads calculated by integrating earth pressures recorded by the array of earth pressure cells embedded flush with the surface of the concrete slab that formed the inside face of the bulkhead. However, the load cell data were judged to be more reliable because they record total boundary loads. The earth pressure cells did not provide total bulkhead surface coverage, and are influenced by the method of calibration and by local variations in soil-instrument contact due to soil placement and compaction against the bulkhead. The sum of reinforcement loads from the instrumented layers (four of eight layers) was deduced from maximum strains from strain gauges mounted in pairs (top and bottom) along the length of the steel strips. The distributions of tensile load are summarised in Figures S2 and S3 of the supplementary data to this paper.

The foundation bulkhead for wall SSJ-9 was released until a minimum horizontal load was achieved that corresponded to a maximum displacement of $18 \mathrm{~mm}$. Figure 3(a) shows that the horizontal load against the bulkhead for wall SSJ-9 was reduced by $84 \%$ with respect to the load at the EOC, which is judged to be a significant reduction of foundation support. There was a corresponding $110 \%$ increase in the total reinforcement load from the instrumented layers as horizontal foundation support was reduced (Figure 3(b)).

The foundation bulkhead for wall SSJ-10 with the stepped base reinforcement arrangement was released until a minimum horizontal load was achieved and the maximum displacement was greater than that recorded for wall SSJ-9. The maximum displacement for this wall was $33 \mathrm{~mm}$. However, in this test the maximum reduction in horizontal loads (with respect to EOC) was $36 \%$ after $6 \mathrm{~mm}$ of movement and $23 \%$ reduction at the end of the test. Furthermore, there was a smaller $(60 \%)$ increase in the sum of measured reinforcement loads, as shown in Figure 3(b). This indicates that the truncated reinforcement lengths at the bottom of the reinforced soil zone were not long enough to anchor the reinforced soil mass and thus develop compensating horizontal load resistance as foundation support was decreased. This hypothesis is supported by the following two observations.

- there was an additional $5 \mathrm{~mm}$ of movement of the bottom facing panel between the EOC and the beginning of bulkhead release.

- At the time of excavation, a fully developed failure mechanism was observed propagating from the bottom of the bulkhead and behind the reinforced soil mass, as illustrated in Figure 4.

This failure mechanism was detected during layer-by-layer excavation of the soil by mapping the distortions in thin layers of lime that were placed at $0.25 \mathrm{~m}$ vertical intervals in the foundation soil and backfill soil at the time of construction. 


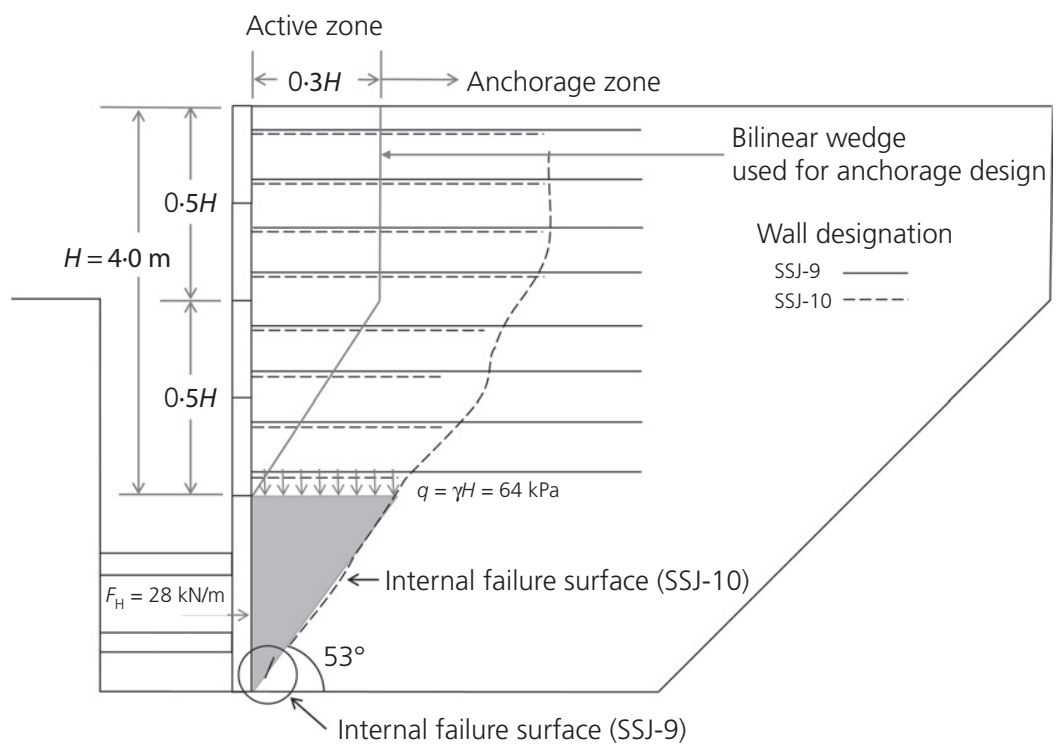

Figure 4. Bilinear design wedge and soil failure surfaces observed during excavation of walls SSJ-9 and SSJ-10 and computed bulkhead reaction using simple wedge analysis for foundation of wall SSJ-10 at end of test

However, there are no records available to indicate at what bulkhead displacement the internal failure was triggered. Only a very short failure surface at the heel of the bulkhead was detected during excavation of wall SSJ-9.

The result of a simple wedge analysis for wall SSJ-10 is also plotted on Figure 4. The geometry of the observed failure wedge in the foundation soil at the time of excavation is used in this analysis together with the peak soil friction angle $\phi=38^{\circ}$ and the interface friction angle between the concrete surface of the bulkhead and the soil, assumed to be $2 \phi / 3$. The active horizontal force acting against the bulkhead was computed as $F_{\mathrm{H}}=28 \mathrm{kN} / \mathrm{m}$, which matches the measured value of $28 \mathrm{kN} / \mathrm{m}$. This is further corroboration that an active failure state was achieved in the foundation at the end of this test.

Vertical (footing) loads at the top of the bulkhead are plotted in Figure 3(c). The vertical load at comparable displacements of about $18 \mathrm{~mm}$ is greater for the less heavily reinforced wall (SSJ-10). Vertical loads for both walls are greater than the selfweight of the concrete facing panels. This is ascribed to interface friction between the back of the facing panels and the soil, plus additional down-drag loads due to hanging-up of the backfill soil on the connections between the facing panels and the reinforcement strips. The ratio of total vertical load to facing self-weight is 1.3 and 1.4 for walls SSJ-9 and SSJ-10 respectively at EOC, but these values increase to 1.5 and 2.0 at the end of each test. Based on a review of instrumented steel strip walls in the field, Damians et al. (2013) concluded that a ratio of $2 \cdot 0$ is typical. This value is also in accordance with recommendations for the design of the bearing pads located at the horizontal joints between incremental concrete panels in the USA (Berg et al., 2009).

Wall deformations are plotted in Figure 5. The deformations are with respect to the original toe of the wall face at the beginning of wall construction. Wall SSJ-9 moved outward by a maximum of $6 \mathrm{~mm}$ at the footing during construction, and wall SSJ-10 moved $20 \mathrm{~mm}$. Recalling that the footing was horizontally unrestrained, resistance to horizontal deformation of the reinforced soil mass during construction was therefore due to resistance at the foundation surface. In a field application, horizontal movement of the footing during construction over a competent foundation would be even less due to shear resistance at the base of the footing and embedment at the toe of the wall. From a practical point of view, wall SSJ-9, with the longer reinforcement layers, remained vertical during construction (e.g. maximum out-of-vertical alignment between any two panels over the height of the wall was $2 \mathrm{~mm}$ at EOC). Wall SSJ-10, with the shorter reinforcement lengths in a stepped base arrangement, developed a concave-out wall displacement profile. The maximum out-of-alignment between any two panels was $16 \mathrm{~mm}$ or about $0.4 \%$ of wall height $H$ at EOC. Typical anticipated deformation for steel strip reinforced soil walls with $L / H=1$ is about $0 \cdot 4 \%$ according to Holtz et al. (2008).

The maximum computed value is reasonably close to the specified $0 \cdot 5 \%$ limit in BS 8006 (BSI, 2010) for all reinforced soil wall types. Recommended or expected deformations for 


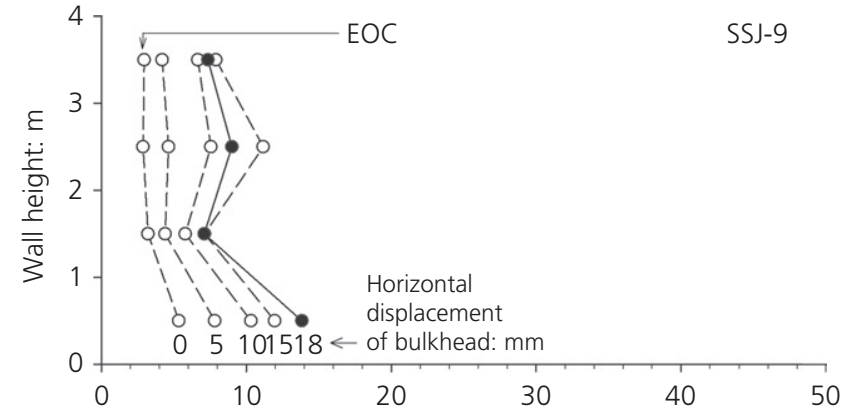

(a)

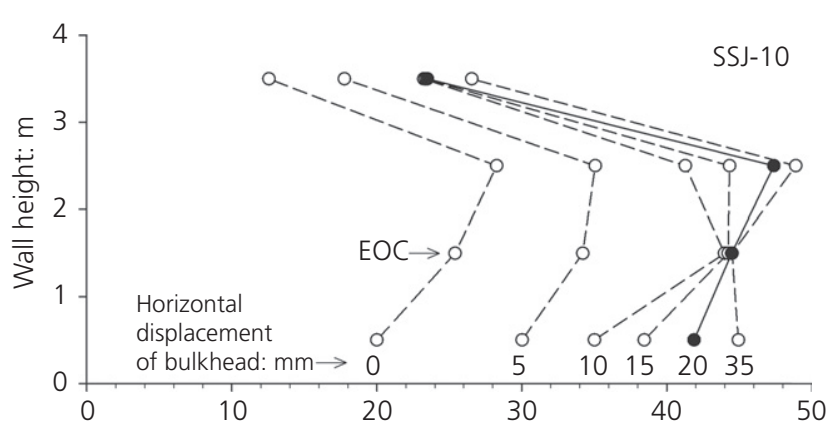

(b)

Horizontal displacement of facing: $\mathrm{mm}$

Figure 5. Facing displacements at EOC and during displacement of foundation bulkhead. Solid black symbols denote wall deformations at maximum similar bulkhead toe displacement (i.e. $18 \mathrm{~mm}$ for SSJ-9 and $20 \mathrm{~mm}$ for SSJ-10). EOC for SSJ-10 is taken as the start of bulkhead displacement

reinforced soil walls vary widely between jurisdictions for different wall types (e.g. Bathurst et al., 2010). However, both walls were judged to have exhibited good performance at the EOC based on the out-of-vertical serviceability criterion of $3 \%$ of wall height specified in Japan (PWRC, 2014). There were no obvious signs of poor performance such as failure scarps or slumps at the backfill surface. The only visual indication of marginal or insufficient load capacity for SSJ-10 with the short stepped base reinforcement configuration was the movement of the bottom panel observed between the EOC and the beginning of bulkhead release noted earlier.

Measured maximum steel strip tensile loads at the EOC and during bulkhead release are plotted in Figure 6. The location of the maximum load $\left(T_{\max }\right)$ in the reinforcement layers was typically at the strain gauge location closest to the connection or within $0.75 \mathrm{~m}$ of the back of the wall face (see Figures S2 and $\mathrm{S} 3$ in the supplementary data). This observation is consistent with the additional down-drag loads generated due to relative downward soil movement directly behind the facing panels during construction. These down-drag loads become greater when the toe of the wall moves further outward during postconstruction foundation bulkhead release. Elevated tensile

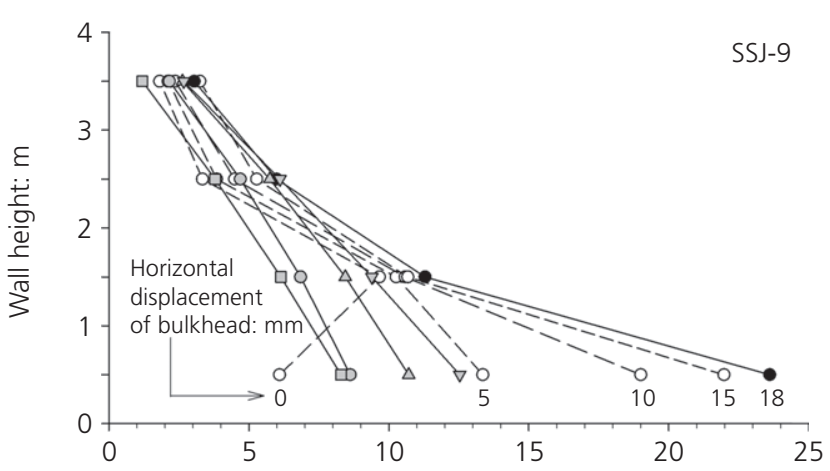

(a)

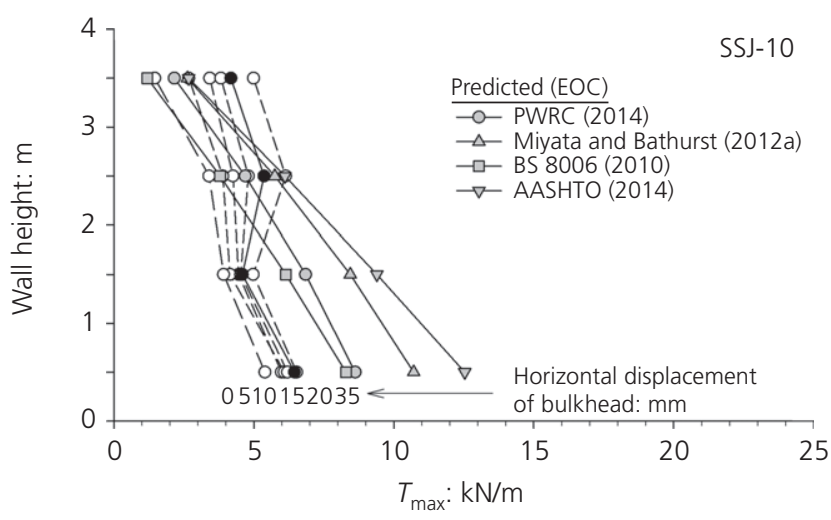

(b)

Figure 6. Measured and predicted reinforcement loads $\left(T_{\max }\right)$ at EOC and measured loads during horizontal displacement of the bulkhead. Solid black symbols for measurement data correspond to loads at similar maximum horizontal bulkhead toe displacements (i.e. $18 \mathrm{~mm}$ for SSJ-9 and $20 \mathrm{~mm}$ for SSJ-10)

loads close to the back of the facing in steel strip reinforced soil walls and tapering off with distance towards the free end of the reinforcing elements have been reported for instrumented field walls of this type and in numerical simulations of the same structures (Damians et al., 2015; Yu et al., 2015). The decrease in tensile load with distance from the facing, which is detectable in most layers at large bulkhead displacement in Figures S2 and S3, is consistent with the notion of tensile load shedding from the steel strip inclusions to the surrounding soil. Figure 6 shows that, with the exception of layer 3 in wall SSJ-9, the initial EOC loads are very similar in magnitude (see measured data plots corresponding to a horizontal displacement of $0 \mathrm{~mm}$ ). This observation suggests that the initial load in this layer is anomalous. There are no records in the source materials explaining why this may have occurred. This discrepancy could be related to local variations in construction and compaction technique. Local elevated reinforcement loads in steel strip reinforced walls have been attributed to compaction effects in other instrumented structures (Bathurst et al., 2009). 
The sum of maximum loads from the four instrumented reinforcement layers for the shorter base length wall at EOC is about $70 \%$ of the total load from the same layers in wall SSJ-9 constructed with longer and uniform reinforcement lengths (Figure 3(b)). During bulkhead release, the reinforcement loads in wall SSJ-9 with longer length increased markedly, particularly for the bottom layer (Figure 6(a)). For wall SSJ-10 with shorter reinforcement lengths at the bottom of the wall, most of the additional reinforcement load is taken by the upper reinforcement layers (Figure 6(b)). This is likely because of the reduced length of the bottom layers followed by the development of the soil failure mechanism identified in Figure 4 and discussed later.

\section{Implications for wall design and performance}

Predicted unfactored (nominal) reinforcement loads for the EOC case using four different approaches for estimating reinforcement loads for internal stability analysis and design are superimposed on Figure 6. The maximum predicted loads are computed using the simplified method (AASHTO, 2014) while the lowest correspond to the method described in BS 8006 (BSI, 2010). The methods of PWRC (2014) and Miyata and Bathurst (2009) give results that fall between these approaches. The BS 8006 method gives the lowest load predictions because this method allows the user to include the (apparent) cohesive component of soil shear strength (if this component of soil shear strength is judged to be available for the life of the structure - the assumption made here.) The Miyata and Bathurst (2009) method is a modified version of the coherent gravity method adopted by PWRC (2014). The modification appears in the magnitude of the empirical coefficients used to define the coefficient of earth pressure with depth below the top of the wall. Details are described by Bathurst et al. (2008, 2009) and Miyata and Bathurst (2009).

The plots in Figure 6 show that each load method gives the same set of predictions regardless of reinforcement arrangement (i.e. uniform or stepped base). With the exception of layer 3 in wall SSJ-9 (discussed earlier), the four methods are typically conservative (safe) for unfactored load design of both walls for the EOC case. At the end of testing the maximum measured reinforcement loads for wall SSJ-9 were greater than the predicted EOC loads in all but one case. This was not true for wall SSJ-10 because greater reinforcement loads for the bottom two layers did not increase substantially. This is attributed to the difficulty mobilising larger tensile load in the bottom reinforcement layers due to their reduced length.

Actual factors of safety against tensile rupture of the steel reinforcement strips can be computed directly knowing the ultimate strength $(400 \mathrm{MPa})$ and the allowable strength $(140 \mathrm{MPa})$ of the reinforcement steel at the time of the tests. For simplicity, the cross-sectional area of the steel strips was

\begin{tabular}{|c|c|c|c|c|}
\hline \multirow[t]{3}{*}{ Stage } & \multicolumn{4}{|c|}{$\begin{array}{c}\text { Minimum FOS and } \\
\text { (corresponding layer number) }\end{array}$} \\
\hline & \multicolumn{2}{|c|}{ Ultimate } & \multicolumn{2}{|c|}{ Allowable } \\
\hline & $\begin{array}{c}\text { SSJ-9 } \\
(L=4 \mathrm{~m})\end{array}$ & $\begin{array}{c}\text { SSJ-10 } \\
(L \text { variable })\end{array}$ & $\begin{array}{c}\text { SSJ-9 } \\
(L=4 \mathrm{~m})\end{array}$ & $\begin{array}{l}\text { SSJ-10 } \\
\text { (L variable }\end{array}$ \\
\hline EOC & $23(3)$ & $36(1)$ & $8.0(3)$ & $13(1)$ \\
\hline $\begin{array}{l}\text { Reduced footing } \\
\text { support }\end{array}$ & $8 \cdot 1(1)$ & $29(1)$ & $2 \cdot 8(1)$ & $10(1)$ \\
\hline
\end{tabular}

Table 1. Minimum (actual) FOS against tensile failure of steel reinforcement layers. Values in parentheses are the corresponding layer number, with layer 1 being the bottom layer of steel strips

not reduced to account for possible corrosion as would be the case for a typical field project. The results of factor of safety (FOS) calculations for tensile failure are summarised in Table 1. The results show that the most critical (lowest) value was FOS $=10$ based on allowable tensile strength and this corresponds to the bottom layer in the stepped base wall. This is interpreted to mean that there was an adequate margin of safety against tensile over-stressing of the reinforcement layers in this wall despite the composite failure mechanism that developed during bulkhead displacement.

Table 2 shows estimated FOS values against pullout failure. In situ pullout tests were not carried out on the steel strips in this investigation, but pullout capacity was estimated using the empirical-based three-parameter exponential (default) model proposed by Miyata and Bathurst (2012b). This model was originally calibrated against a database of in situ pullout tests performed on ribbed steel strip specimens reported in the Japanese literature, including tests carried out at PWRI with soils similar to those in the full-scale wall tests described here. The empirical coefficients in the pullout model were selected to give a mean bias value of 1.0 (ratio of measured to predicted pullout load) using all available data. The anchorage length of each layer is required in order to estimate pullout capacity. In this study, the method recommended by AASHTO (2014) and PWRC (2014) was used. This method defines the active soil zone as a bilinear wedge propagating up from the heel of the facing at a slope of $0 \cdot 6-1 \cdot 0$ horizontal to vertical to a height of $H / 2$ above the toe and then extending vertically to the backfill surface (see Figure 4). The anchorage length of each layer is the distance between the back of the reinforced zone and the free end of the reinforcement layer. Table 2 shows that the most critical FOS against pullout is 1.5 and this corresponds to the bottom layer in wall SSJ-9. This may appear at first to be counter-intuitive with respect to the higher FOS for the same layer in wall SSJ-10 with reduced reinforcement length. However, recall that the maximum load in this layer was also low, which is attributed to the difficulty in mobilising a larger 


\begin{tabular}{|c|c|c|}
\hline \multirow[t]{2}{*}{ Stage } & \multicolumn{2}{|c|}{$\begin{array}{l}\text { Minimum FOS and } \\
\text { (corresponding layer number) }\end{array}$} \\
\hline & $\begin{array}{c}\text { SSJ-9 } \\
(L=4 \mathrm{~m})\end{array}$ & $\begin{array}{c}\text { SSJ-10 } \\
(L=\text { variable })\end{array}$ \\
\hline EOC & $4 \cdot 4(3)$ & $2 \cdot 3(1)$ \\
\hline Reduced footing support & $1 \cdot 5(1)$ & $1.9(1)$ \\
\hline \multicolumn{3}{|c|}{$\begin{array}{l}\text { Table 2. Minimum FOS against pullout failure using measured } \\
\text { maximum tensile load, estimated anchorage length (calculated } \\
\text { using AASHTO (2014) and PWRC (2014)) and pullout capacity } \\
\text { model of Miyata and Bathurst (2012b); layer } 1 \text { is the bottom layer } \\
\text { of steel strips }\end{array}$} \\
\hline
\end{tabular}

tensile load in the reinforcement layer due to its reduced length. In the USA, the load and resistance factor design (LRFD) approach is used for ultimate pullout limit state design (AASHTO, 2014). However, load and resistance factors have been selected to give an equivalent minimum acceptable FOS of 1.8 (Huang et al., 2012); in Japan, this value is 2.0 (PWRC, 2014). Hence, the loss of footing support leads to an unacceptably low FOS against pullout for wall SSJ-9 based on USA and Japanese practice assuming that the estimate of pullout capacity is reasonable.

\section{Conclusions}

The results of two nominal identical full-scale steel strip reinforced soil wall tests varying only with respect to reinforcement arrangement have been reported here. One wall was constructed with uniform reinforcement layer lengths and the other was constructed with a stepped base arrangement that included shorter reinforcement lengths at the bottom of the wall. Following construction, wall toe support was reduced by retracting the bulkhead supporting the foundation soil. The main performance observations from this study are summarised as follows.

The stepped base arrangement with shorter reinforcement lengths resulted in larger wall lateral deformation at the base of the wall and greater facing distortion at the end of construction (EOC) and during subsequent reduction of foundation support than the companion wall with longer and uniform length reinforcement layers.

- Maximum tensile reinforcement loads at the EOC, with the exception of one layer in the wall with uniform reinforcement length, were similar.

- A fully developed soil failure mechanism was generated through the foundation soil and behind the reinforcement layers in the stepped base wall test after reduction of toe support. Failure surfaces were not observed in the backfill soil for the wall constructed with longer uniform length reinforcement layers.
- The observed composite failure surface that was generated in the wall with the stepped base reinforcement geometry after large foundation displacements extended well beyond the two-part wedge geometry that is assumed for pullout design of steel strip reinforced soil walls (Figure 4). It is thus not surprising that this wall experienced much larger deformations than the companion wall with longer uniform reinforcement layers once failure was initiated from the foundation.

Some implications for the design and performance of these structures can be summarised as follows.

- Estimates of unfactored maximum tensile loads at the EOC using current design methods (e.g. AASHTO, 2014; BSI, 2010; PWRC, 2014) and the method proposed by Miyata and Bathurst (2012a) were typically conservative (safe) for both the uniform and stepped base reinforcement layer arrangements.

- Loss of toe support for the wall with uniform reinforcement length resulted in reinforcement loads that were greater than the predicted EOC values, particularly for those layers located close to the bottom of the wall. For the wall with the stepped base reinforcement arrangement, the under-prediction of measured loads after loss of toe support was restricted to the two top (instrumented) layers.

- Despite large foundation lateral deformations, the reinforced soil zone in each wall remained intact and there were no visual indications of soil failure mechanisms within the reinforced soil. The integrity of the reinforced soil zones was confirmed by estimates of factors of safety against rupture and pullout limit states that were all greater than $1 \cdot 0$. However, loss of toe support did reduce the margin of safety against pullout at the bottom of the wall with uniform reinforcement lengths to a value less than the specified minimum values in some design codes.

The results reported here suggest that for walls constructed over competent foundations with similar reinforcement arrangements (i.e. uniform and stepped base) and lengths, the distribution and magnitude of tensile loads may not be sensitive to reinforcement length arrangement. This is the implicit assumption in current reinforcement load models used to predict reinforcement loads in steel reinforced soil walls under operational conditions (EOC). However, for walls with a stepped base configuration with short reinforcement lengths at the bottom of the wall, loss of toe support can lead to composite soil failure mechanisms that are not considered in conventional internal stability analysis and design of these structures.

Finally, the observations reported here will apply only to field walls that are a reasonable match to the test conditions in this study. For example, external stability modes of failure are possible in field cases, but could not develop due to the size and 
boundary conditions of the models in this investigation. The results of this investigation provide important qualitative and quantitative insights, but readers should use caution when applying the lessons learned in this study to field structures.

\section{Acknowledgements}

The analyses described here were carried out with funding awarded to the second author by the Japan Ministry of Education, Culture, Sports, Science and Technology (Grantin-Aid for Scientific Research (B) no. 24360195) and the Japan Ministry of Defense. Additional funding was provided by the collaborative project on 'Sustainability of Reinforced Soil Walls' supported by the Public Works Research Institute (PWRI), Nippon Expressway Research Institute Company Limited, the National Defense Academy of Japan and 11 private companies in Japan. The first author is grateful for their financial support during a sabbatical visit to the National Defense Academy in Japan from his home institution (Royal Military College of Canada).

\section{REFERENCES}

AASHTO (American Association of State Highway and Transportation Officials) (2014) LRFD Bridge Design Specifications, 7th edn. AASHTO, Washington, DC, USA.

Alzamora DE and Anderson SA (2009) Review of mechanically stabilized earth wall performance issues. Proceedings of the Transportation Research Board (TRB) 2009 Annual Meeting. Transportation Research Board, Washington, DC, USA (CD-ROM).

Bathurst RJ, Nernheim A and Allen TM (2008) Comparison of measured and predicted loads using the coherent gravity method for steel soil walls. Proceedings of the Institution of Civil Engineers - Ground Improvement 161(3): 113-120.

Bathurst RJ, Nernheim A and Allen TM (2009) Predicted loads in steel reinforced soil walls using the AASHTO simplified method. ASCE Journal of Geotechnical and Geoenvironmental Engineering 135(2): 177-184.

Bathurst RJ, Miyata Y and Allen TM (2010) Invited keynote paper: Facing displacements in geosynthetic reinforced soil walls. In Proceedings of Earth Retention Conference 3 (ER2010), Bellevue, WA, USA (Richard F, Youssef MA Hashash and Pedro A (eds)). ASCE Geo-Institute, Reston, VA, USA, pp. 422-459.

Bathurst RJ, Nernheim A and Allen TM (2011) Response to discussion of "predicted loads in steel reinforced soil walls using the AASHTO simplified method' by Bathurst RJ, Nernheim A and Allen TM (2009) 135(2): 177-184. ASCE Journal of Geotechnical and Geoenvironmental Engineering 137(6): 1307-1310.

Bathurst RJ, Miyata Y, Konami T and Miyatake H (2015) Stability of multi-anchor soil walls after loss of toe support. Géotechnique, http://dx.doi.org/10.1680/geot.15.P.041.

Berg RR, Christopher BR and Samtani NC (2009) Design and Construction of Mechanically Stabilized Earth Walls and
Reinforced Soil Slopes, vol. I. National Highway Institute, Federal Highway Administration, U.S. Department of Transportation, Washington, DC, USA.

BSI (2010) BS 8006: Code of practice for strengthened/ reinforced soil and other fills. BSI, Milton Keynes, UK.

CGS (Canadian Geotechnical Society) (2006) Canadian Foundation Engineering Manual 4th edn. BiTech Publishers, Richmond, BC, Canada.

Damians IP, Bathurst RJ, Josa A, Lloret A and Albuquerque PJR (2013) Vertical facing loads in steel reinforced soil walls. ASCE Journal of Geotechnical and Geoenvironmental Engineering 139(9): 1419-1432.

Damians IP, Bathurs RJ, Josa A and Lloret A (2015) Numerical analysis of an instrumented steel reinforced soil wall. ASCE International Journal of Geomechanics 15(1): 04014037 , http://dx.doi.org/10.1061/(ASCE)GM.1943-5622.0000394.

GEO (Geotechnical Engineering Office) (2002) Geoguide 6: Guide to Reinforced Fill Structure and Slope Design. GEO, Hong Kong, China.

Holtz RD, Christopher BR and Berg RR (2008) Geosynthetic Design and Construction Guidelines. Federal Highway Administration, Washington, DC, USA, FHWA NHI07-092.

Huang B, Bathurst RJ and Allen TM (2012) Load and resistance factor design (LRFD) calibration for steel strip reinforced soil walls. ASCE Journal of Geotechnical and Geoenvironmental Engineering 138(8): 922-933.

Kumada T, Sakai S, Sakai T and Onodera S (1994) Full-scale test on global stability of reinforced soil wall, part 2: behaviour of steel-strip reinforced soil walls. In Proceedings of the 49th Japan Society of Civil Engineers Annual Meeting, Sapporo, Japan. Japan Society of Civil Engineers, Tokyo, Japan, pp. 1666-1667 (in Japanese).

Miyata Y and Bathurst RJ (2009) Measured and predicted loads in multi-anchor reinforced soil walls in Japan. Soils and Foundations 49(1): 1-10.

Miyata Y and Bathurst RJ (2012a) Measured and predicted loads in steel strip reinforced $c-\phi$ soil walls in Japan. Soils and Foundations 52(1): 1-17.

Miyata Y and Bathurst RJ (2012b) Analysis and calibration of default steel strip pullout models used in Japan. Soils and Foundations 52(3): 481-497.

Miyata Y, Bathurst RJ and Miyatake H (2015) Performance of three geogrid reinforced soil walls before and after foundation failure. Geosynthetics International 22(4): 311-326, http://dx.doi.org/10.1680/gein.15.00014.

Onodera S, Dobashi K, Misawa K et al. (1994) Full-scale test on global stability of reinforced soil walls, part 1: outline of test and earth pressure against facing panels. In Proceedings of 49th Japan Society of Civil Engineers Annual Meeting, Sapporo, Japan. Japan Society of Civil Engineers, Tokyo, Japan, pp. 1670-1671 (in Japanese).

PWRC (Public Works Research Center) (1995) Technical Report on Rational Design Method of Reinforced Soil Walls. PWRC, Tsukuba, Japan (in Japanese). 
PWRC (2014) Design Method, Construction Manual and Specifications for Steel Strip Reinforced Retaining Walls, 4th edn. PWRC, Tsukuba, Japan (in Japanese).
Yu Y, Bathurst RJ and Miyata Y (2015) Numerical analysis of a mechanically stabilized earth wall reinforced with steel strips. Soils and Foundations 55(3): 536-547.

\section{WHAT DO YOU THINK?}

To discuss this paper, please email up to 500 words to the editor at journals@ice.org.uk. Your contribution will be forwarded to the author(s) for a reply and, if considered appropriate by the editorial panel, will be published as discussion in a future issue of the journal.

Proceedings journals rely entirely on contributions sent in by civil engineering professionals, academics and students. Papers should be 2000-5000 words long (briefing papers should be 1000-2000 words long), with adequate illustrations and references. You can submit your paper online via www.icevirtuallibrary.com/content/journals, where you will also find detailed author guidelines. 